Issa Fowai

Jianhua Zhang

Ke Sun

Bin Wang

http://dx.doi.org/10.21278/brod72106

ISSN 0007-215X

eISSN $1845-5859$

\title{
STRUCTURAL ANALYSIS OF JACKET FOUNDATIONS FOR OFFSHORE WIND TURBINES IN TRANSITIONAL WATER
}

UDC 621.224.3:621.3.016.3

Professional paper

\begin{abstract}
Most offshore wind turbines (OWT) recently installed in Europe, China and North America are in shallow water. However, unlocking the full potential of OWT lies in deeper waters. Jacket substructures have presented themselves as a reliable foundation concept for transitional water depth. This study focuses on the structural static and dynamic analysis of the traditional jacket substructures (with $\mathrm{X}$ and $\mathrm{K}$ bracing) and the recently patented three-legged twisted jackets (with a twisted angle of 30 and 60 degrees) for deployment in transitional water (beyond $60 \mathrm{~m}$ ). To facilitate comparison, the dimensions of all the jackets remain the same, while the geometric configurations are distinct. Static analysis was implemented to better understand the global load bearing behaviour of the jackets. First, the global displacement patterns at the tower top are compared. The individual reactions at mud-line were investigated, followed by the evaluation of the maximum von Mises stress. Subsequently, this research went on to investigate the effect of dynamic loading. In this dynamic analysis, three main critical points were considered, including the wave point $(67 \mathrm{~m})$, the platform and the tower top. A modal analysis was performed to compute the mode shapes and natural frequencies for all the jackets. The first five modes of all the jackets were also checked against the results available for the OC4 project. A similar analytical approach was adopted for the structural design of monopile or tripod foundations for offshore wind turbines. The results showed that in the static analysis both the traditional jackets and the twisted jackets were safe under the provided load combination. The twisted jacket proved to possess excellent structural behaviour compared to the traditional four-legged jackets, while maintaining the merits of lower material usage with fewer nodes. Analysing the von Mises stress revealed that the maximum stress occurred at the transition piece and close to the working platform. The modal analysis results of the jackets demonstrated that the twisted jackets (30 and 60 degrees) with the first natural frequency of 0.29 and $0.31 \mathrm{~Hz}$ fell under the soft-stiff design category, whereas the traditional four-legged jackets were classified as stiff-stiff designs. The discovered structural performance of OWTs equipped with various jacket foundations contributes to the preliminary structural selection and optimal design of foundations of OWTs to be installed in transitional water.
\end{abstract}

Keywords: OWT; Transitional Water; Natural Frequencies; Jackets; Dynamic Analysis 


\section{Introduction}

In recent years, there has been tremendous development in Offshore Wind Turbine (OWT) farm designs; both the water depth and the distance to shore are anticipated to keep increasing in the next few decades. An important engineering challenge faced today is the development of lightweight offshore wind structures with minimal structural failure. This is the firm priority for many researchers in the field. However, in order to curb the current rate of accidents or structural failure of offshore wind structures, substantial structural load simulation analysis is essential for the design of both the rotor nacelle assembly and the support structure. Jacket foundations have been used as a suitable substitute for other foundation structures in transitional water depth (beyond $60 \mathrm{~m}$ ) in many parts of the world, and this trend will continue to grow in markets where monopile is not yet consolidated. Jacket foundations perform well in the transitional water depth mainly because of their lighter structural mass and greater structural stiffness. With lower dependency on soil compared to other structures forms, jacket foundations are preferable for installation under soft soil conditions because the structure is less susceptible to lateral loadings that might cause a pile foundation to tilt. Stability of jacket substructures makes it a better choice for larger and heavier wind turbines in the future. At the same time, however, the cost of jackets is relatively higher than the monopile, which is predominant in the offshore wind industry. Although the cost of jacket substructure is still high, the progress in its commercial application is promising. At the end of 2018, 119 Jacket foundations were installed in European seas, accounting for 24.5 percent of all installed foundations in 2018 and with a cumulative total of 403 grid-connected Jacket-offshore wind turbines [1-3]. The share of jacket foundations rose due to construction at Beatrice 2, EOWDC and East Anglia 1 Projects. The East Anglia 1 project with 102 offshore jacket turbines will be one of the world's largest offshore wind farms when it becomes operational in 2020. Jacket foundations have also been used for two other noticeable deep water development projects, i.e. Beatrice $(45 \mathrm{~m})$ and Alpha Ventus (30 m), supporting large 5MW turbines [4]. Several innovative concepts for OWT jacket foundations have been proposed [5-7]. For instance, the newly patented iJacket design is expected to provide a 25-30 percent weight reduction in steel.

Currently, a substantial number of researches have been carried out on the structural behaviour of Jacket foundations for offshore wind turbines. Some researchers investigated the response of the wind turbines with jacket foundations under wind load and wave conditions [815], mainly focusing on the dynamic time response of these support structures. The dynamic stiffness and damping of jacket foundations were studied by Latini [16]. Hafele et al. [17] conducted a comparative study on the structural optimization of jacket foundations for offshore wind turbines, providing crucial details on the geometry, costs and structural design code checks for jacket foundations. In ref. [18] a novel scheme for OWT jacket optimization was proposed. Subsequently, researches on the fatigue characteristic have been undertaken by notable researchers. Nelson and Yann [19] developed a fatigue life analysis tool for Jacket substructure in an offshore wind farm. Wu et al. [20] studied the fatigue calculation of offshore jacket foundations for monitoring. Glisic et al. [21] made a comparative study on the two main approaches for structural analysis in the offshore industry: the Integrated Design Approach (IDA) and the Sequential Design Approach (SDA). Further details on the design and analysis of OWT jacket substructures and the influence of subsequent modification on fatigue performance can be found in Augustyn et al. [22] Zhang et al. [23] investigated the design challenges of uncertainties associated with design parameters and modelling errors using Monte Carlo simulations, in order to determine the key structural design parameters and to determine the optimal balance between design parameters and design requirements for an OWT jacket foundations. Yeter et al. [24] assessed the ultimate strength of OWT jacket structures under progressive bending loading. Han et al. [25] discussed the effect of soil properties on the structural behaviour of offshore jacket structures. Although initial studies on the 
unconventional three-legged twisted jacket substructure have highlighted its potential comparative industrial advantages over the traditional four-legged jacket, more research is required to provide a comprehensive evaluation of both the conventional jacket with four legs and the three-legged twisted jacket [30]. The aim of this research is to investigate both the static and dynamic characteristics of four commercial popular jacket sub-structures that are deployable in moderate water depth. Static analysis was studied to understand the global load bearing capacity of all jackets. Static Pushover analysis was not covered considering the load characteristics available. Subsequently, to evaluate the dynamic characteristics of the jacket sub-structures, a dynamic response simulation due to wave and wind loads are performed in time-domain with a time duration of 120s. Furthermore, modal analysis is performed to assess the natural modes of the system in order to avoid resonance.

\section{Theoretical Background and Simulation Load Cases}

\subsection{Static Analysis and Ultimate Limit State Checks}

In this work, statics analysis was performed with realistic loads to allow us to compare results of the jacket foundations. Details on these load cases are provided in Table 1 . The gravity load due to self-weight of the jackets and the tower was considered. These loads were applied separately and together. Due to the linear characteristics of the structure, the sum of the outputs acquired by applying the load components individually equals the outputs when the components are applied together. The ultimate limit state (ULS), which corresponds to the maximum load carrying capacity of the structure is one of the main design limit states, where extreme loads are applied to the structure. For failure of OWTs under ultimate load, [26, 27] put forward several examples. [28] was used for design code checking. This standard is applicable to all steel offshore wind structures with minimum yield strength less than or equal to $500 \mathrm{Mpa}$. The equations used for checking compressive, tensional members including members subjected to combined axial compression and bending, and axial compression and bending are given below, respectively [26].

$$
\begin{gathered}
N_{S d} \leq N_{c, R d}=\frac{A f_{C}}{\gamma_{M}} \\
N_{S d} \leq N_{t, R d}=\frac{A f_{y}}{\gamma_{M}}
\end{gathered}
$$

In the above equations, $\mathrm{N}_{\mathrm{Sd}}$ denotes the design axial force for both compressive and tensional members; the characteristic axial compressive force is given as $\mathrm{f}_{\mathrm{c}}$ and for tensional members the yield strength is given as $\mathrm{f}_{\mathrm{y}}$; A represents the cross sectional area of a member and $\gamma_{M}$ is the material factor. According to the standard, tubular members subjected to combined axial compression and bending loads are designed to satisfy the following condition at all crosssections along their length. The members subjected to combined axial tension and bending loads should be designed to satisfy this condition:

$$
\left(\frac{N_{S d}}{N_{t, R d}}\right)^{1.75}+\frac{\sqrt{M^{2} y, S d+M^{2} z, S d}}{M_{R d}} \leq 1.0
$$

Where $\mathrm{M}_{y, S d}$ is the design bending moment about the member $\mathrm{y}$-axis (in plane) of the member, $\mathrm{M}_{Z, S d}$ is moment about the $\mathrm{z}$-axis (out of plane) and $\mathrm{M}_{R d}$ is design bending moment resistance; $\mathrm{N}_{\mathrm{Sd}}$ denotes the design axial force. In the case of members subjected to combined axial 
compression and bending loads, they should be designed in accordance with the condition provided below.

$$
\begin{aligned}
& \frac{N_{S d}}{N_{c, R d}}+\frac{1}{M_{R d}}\left\{\left[\frac{c_{m y} M_{y, S d}}{1-\frac{N_{S d}}{N_{E y}}}\right]^{2}+\left[\frac{c_{m z} M_{z, S d}}{1-\frac{N_{S d}}{N_{E z}}}\right]^{2}\right\}^{0.5} \leq 1.0 \\
& \left(\frac{N_{S d}}{N_{c l, R d}}\right)^{1.75}+\frac{\sqrt{M^{2} y, S d+M^{2}{ }_{z, S d}}}{M_{R d}} \leq 1.0
\end{aligned}
$$

Where $\mathrm{N}_{\mathrm{Sd}}$ is the design axial force; $N_{E y}$ and $N_{E z}$ are the Euler buckling resistance forces corresponding to the member $\mathrm{y}$-axis and z-axis respectively; $\mathrm{C}_{\mathrm{my}}$ and $\mathrm{C}_{\mathrm{mz}}$ are the reduction factors corresponding to the member $y$ and z-axis, respectively.

\subsection{Concept of Modal analysis}

Investigating the natural frequencies of the foundation requires the analysis of the combined structure, i.e. the turbine, tower and the jackets including the piles. In order to provide a cursory overview of the overall jacket behavior, we employed a finite element tool to calculate the natural modes and the corresponding mode shapes. By analyzing the natural frequencies, we can investigate how the foundation vibrates under free motion, i.e. without external loads or excitation. The natural frequency also helps us to classify the foundations into the following categories: soft-soft, soft-stiff and stiff-stiff [31]. The natural frequency of the system depends on two main properties: stiffness and the mass. These properties are variable with respect to time. For instance, marine growth can increase the mass, while corrosion can decrease the stiffness of the structure. During operation, the structure is subjected to harmonic excitation from the rotor. The rotor's rotational frequency is the first excitation known as $1 \mathrm{P}$ and the blade passing frequency which causes the second excitation is known as 3P. It is crucial that the natural frequency of the structure and the rotational frequency of the rotor do not coincide. For all the four jacket foundations we used the Block Lanczos extraction method with 10 extractions [32].

\subsection{Dynamic Analysis}

Dynamic finite element analysis is required to evaluate the time dependent response of the jacket foundations. In ANSYS, the time-history analysis was conducted to determine the dynamic response of the jackets under wave and wind time-dependent loads. In order to study the dynamic response due to wave load, a .txt file with random wave load was uploaded into ANSYS and the displacement graphs are plotted for comparison.

\subsection{Simulation load settings}

An integrated analysis of wind turbines and the support structure considering not only the primary environmental loads (e.g., wind, wave and current loads) but also the accidental loads (e.g., snow and ice loads) is crucial in structural design [15]. Generally, the loads that are considered should include permanent, variable, environmental as well as accidental loads which might occur during the life span of this structure. During its service period, the overall load combination applied to an offshore wind turbine is very complex in nature, especially the environmental loadings. For the purpose of simplicity and without loss of generality, we only included permanent loads like mass of the structures and environmental loads, such as wind, wave and current. Other metocean loadings such as tidal, ice, soil conditions and temperature 
effect were not considered. Additional hydrodynamic load, water in flooded legs and load from marine growth were also neglected. In load combination, we assumed that the loads from wind, wave and current loads acted in the same direction.

The distributed loading including wind loading and wave loading is simplified as point loading to deal with the large-scale structural configurations and improve the computational efficiency. Wind loads on rotor can be obtained from Betz theory, the air density is $1.225 \mathrm{~kg} / \mathrm{m}^{3}$ and the maximum wind speed is $34 \mathrm{~m} / \mathrm{s}$. The Morison formula is applied to calculate the wave force. The wave height and average wave period is $14 \mathrm{~m}$ and $16.7 \mathrm{~s}$, respectively. Wind shear is not included in this paper and the rated wind speed, the rotor thrust is taken to be at its maximum with the normal operation of the turbine. For slender structures, such as the jacket substructure discussed in this study, the wave and current loads can be calculated using Morison's equation and Airy's linear theory with additional assumptions and approximations, with the help of elementary mechanics. The static loads were attached at the tower top as point loads.

Table 1 Static Loads at Tower Top

\begin{tabular}{|c|c|}
\hline Component & Value \\
\hline$F_{X}$ & $740(\mathrm{kN})$ \\
\hline$F_{Y}$ & $-1.5(\mathrm{kN})$ \\
\hline$F_{Z}$ & $-3500(\mathrm{kN})$ \\
\hline$M_{X}$ & $4220(\mathrm{kN} \cdot \mathrm{m})$ \\
\hline$M_{Y}$ & $185(\mathrm{kN} \cdot \mathrm{m})$ \\
\hline$M_{Z}$ & $-43(\mathrm{kN} \cdot \mathrm{m})$ \\
\hline
\end{tabular}

\section{Finite Element Modelling of Jacket Foundations}

\subsection{Turbine Description}

The turbine model only includes the rotor nacelle assembly (RNA) as tower is considered as part of the support structure in this work. In this project, the NREL 5MW baseline turbine was selected to operate on the top of the steel tower, which is supported by the steel jacket substructure. The NREL $5 \mathrm{MW}$ is normally used for code testing and comparison purposes. The technical report by Jonkman et al. [30] defines the structural, aerodynamic and control properties of this wind turbine in detail. The NREL 5MW baseline turbine is a three-bladed horizontal axis upwind machine with variable-speed and collective pitch control. With a nacelle mass of 240t and a rotor mass of 110t, the NREL $5 \mathrm{MW}$ baseline turbine has a hub height of $90.55 \mathrm{~m}$, a rotor diameter of $126 \mathrm{~m}$ and a hub diameter of $3 \mathrm{~m}$. The cut in, rated and cut out wind speed of the NREL 5 MW baseline turbine are $3 \mathrm{~m} / \mathrm{s}, 11.4 \mathrm{~m} / \mathrm{s}$ and $25 \mathrm{~m} / \mathrm{s}$, respectively. The local coordinate system of the turbine blades is depicted in Fig. 1. 
Issa Fowai, Zhang Jianhua, Ke Sun,Bin Wang
Structural Analysis of Jacket Foundations for offshore wind turbines in transitional water

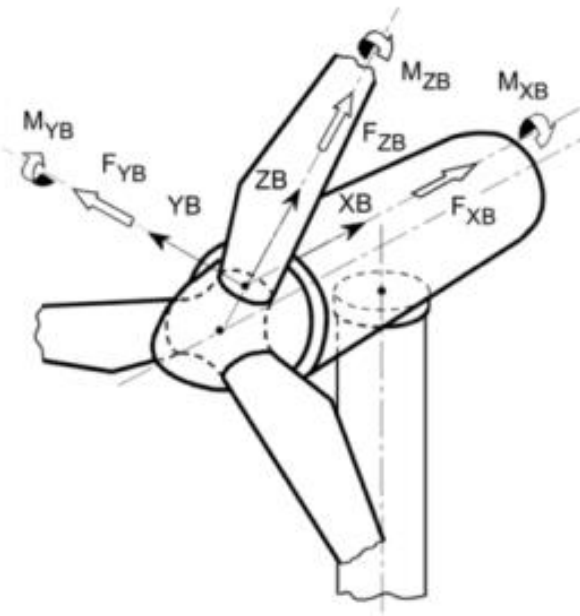

Fig. 1 Local Coordinate System of the turbine

\subsection{Dimensions and material properties of Jackets and Platform}

In this research we compared four jacket foundations, which can be categorized into two groups (conventional four-legged jackets and the twisted jacket foundations). The obvious difference between the two four-legged traditional jackets is the type of bracing. One is X braced and the other is K-braced. For the twisted jacket only the twist angle was altered. The height of the jacket and the tower are 89.5 and 63.5 meters, respectively. The four legs of the jacket form a square with a side length of $30 \mathrm{~m}$ meters at the base. In order to establish a rigid connection between the interface and the tabular tower several rigid beams were added. The dimensions of the traditional jacket foundations are shown in Table 2. Furthermore, we compared them with two recently patented twisted jacket substructures with $30^{\circ}$ and $60^{\circ}$ twisted angle around a vertical guide sleeve. Manufacturing this new innovative twisted jacket design is much less complex than traditional jacket substructures. The twisted jackets design requires fewer braces and fewer nodes, which makes the assembling line less labor intensive and no additional welding is required offshore. The legs and braces of the traditional jacket are designed with different diameters and thickness. The properties are given in Table 2.

Table 2 Dimensions of the Braces for all Traditional Jacket Foundations

\begin{tabular}{|l|c|c|}
\hline Member & Inner diameter [m] & Thickness[m] \\
\hline Vertical braces X1, X2 \& X3 & 0.6 & 0.022 \\
\hline Vertical Braces X4 \& X5 & 0.9 & 0.022 \\
\hline Second level horizontal brace & 0.6 & 0.022 \\
\hline Horizontal Mud line braces & 0.7 & 0.022 \\
\hline Leg at highest Level & 1.17 & 0.034 \\
\hline Leg at lowest level & 1.70 & 0.06 \\
\hline
\end{tabular}


The main dimensions of the traditional-jacket substructure are displayed in Fig. 2. The conventional jackets (four-legged $\mathrm{X}$ and $\mathrm{K}$ bracing) are designed with five layers of vertical braces and two horizontal at $2.7 \mathrm{~m}$ and $45 \mathrm{~m}$ respectively. Leg diameter range from $1.17 \mathrm{~m}$ with $0.034 \mathrm{~m}$ thick at interface to $1.70 \mathrm{~m}$ with thickness 0.06 at foundation level. The tower is modelled with a constant diameter of $3 \mathrm{~m}$. The elevation of the transition piece was set to $6 \mathrm{~m}$ between the jacket and the tower. These dimensions shown below for the tradition jacket align with the dimensions of both the twisted jacket foundations in Fig. 3. The twisted jacket support structure includes a vertical guide sleeve and three elongated guide sleeves positioned around the vertical guide sleeve, and various braces connecting the elongated sleeves and the vertical guide sleeve. For real life application and to provide resistance to thrust, bending, and torsional fatigue, at least one set of braces should be formed in oval, racetrack, obround, or stadium configuration, and horizontal stiffeners are positioned in the transition joint to maximize the strength of the support structure. For this substructure, the basic structural unit used in ANSYS APDL is the beam188, except the platform and interface, which were modelled with shell181. All degrees of freedom (DOFs) of the legs are fixed in the ANSYS model. To improve the rigidity between the tower and the platform additional constraints were imposed in ANSYS. In ANSYS CERIG command was used to increase rigidity. Table 3 lists the material properties used in this study, such as density, Young modulus and Poisson's ratio. In this project, we neglect the plastic deformation of the tubular tower, since we focus on the design and analysis of the jacket.
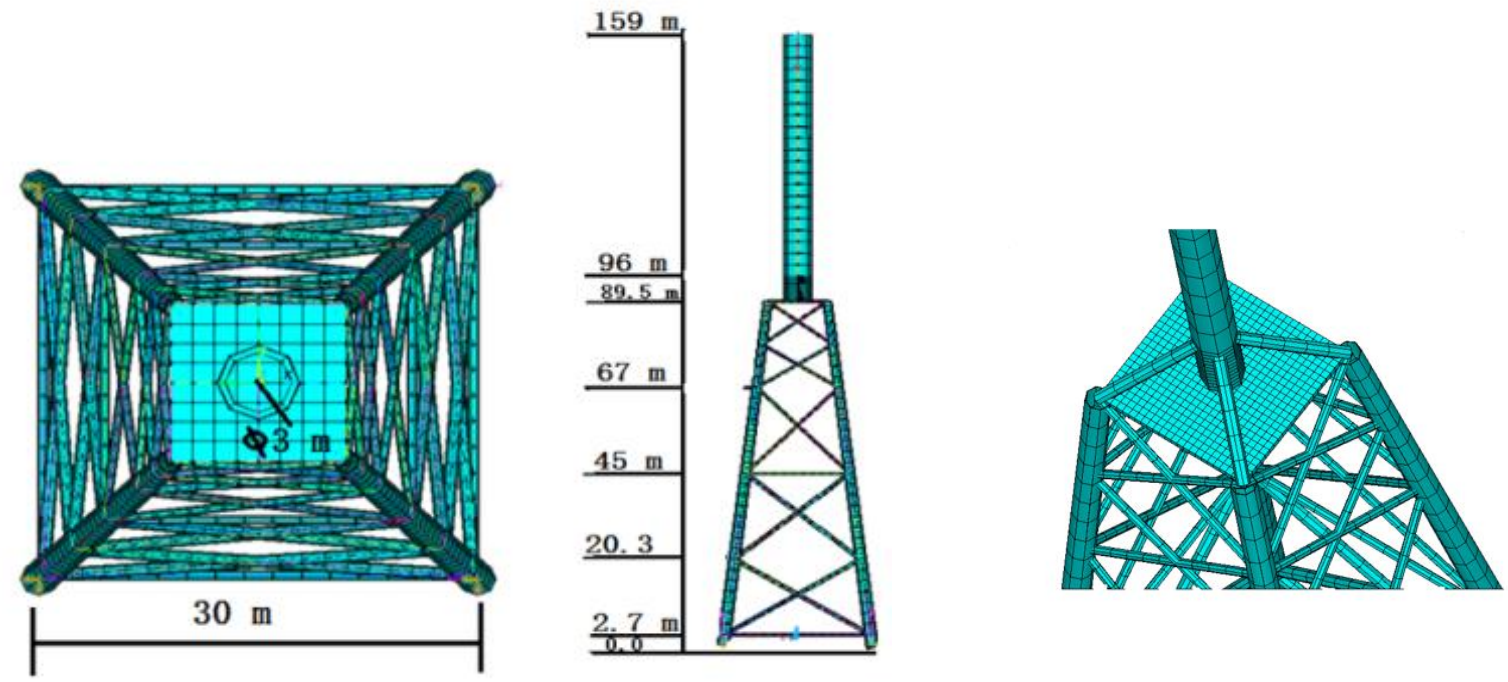

Fig. 2 Dimension of Jacket Foundation

In ANSYS, a variety of tools are available to help adjust the mesh characteristics of the global structure. To improve the calculation accuracy of the platform, a global meshing seed of 0.5 $\mathrm{m}$ was applied to the 12 square meter platform Fig. 4. 
Table 3 FEM Material Properties of the Jackets

\begin{tabular}{|c|c|c|c|c|c|c|}
\hline Place & Material & Element & $\begin{array}{l}\text { Density } \\
\left(\mathrm{kg} / \mathrm{m}^{3}\right)\end{array}$ & $\begin{array}{l}\text { Young's } \\
\text { modulus } \\
\left(\mathrm{N} / \mathbf{m}^{2}\right)\end{array}$ & $\begin{array}{l}\text { Yield } \\
\text { Stress } \\
(\mathbf{P a})\end{array}$ & $\begin{array}{l}\text { Poisson's } \\
\text { ratio }\end{array}$ \\
\hline Jacket & Steel & Beam & 12670 & $2.10 \mathrm{E}+11$ & $4.20 \mathrm{E}+08$ & 0.3 \\
\hline Platform & Steel & Shell & 7850 & $21 E+11$ & I & 0.3 \\
\hline Tower & Steel & Beam & 7850 & $2.10 \mathrm{E}+11$ & $4.20 \mathrm{E}+08$ & 0.3 \\
\hline Interface & Steel & Shell & 7850 & $2.10 \mathrm{E}+11$ & $4.20 \mathrm{E}+08$ & 0.3 \\
\hline Braces & Steel & Beam & 7850 & $2.10 \mathrm{E}+11$ & $4.20 \mathrm{E}+08$ & 0.3 \\
\hline
\end{tabular}

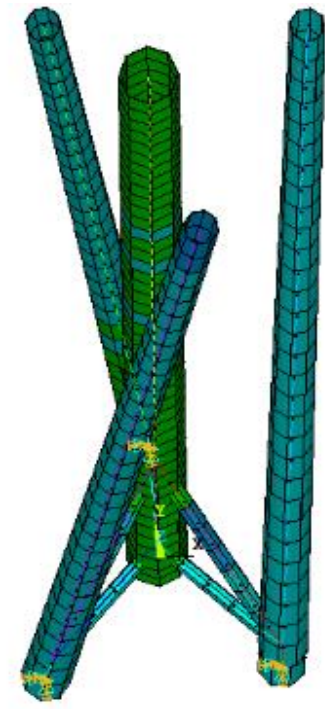

Fig. 3 Twisted Jacket Substructure

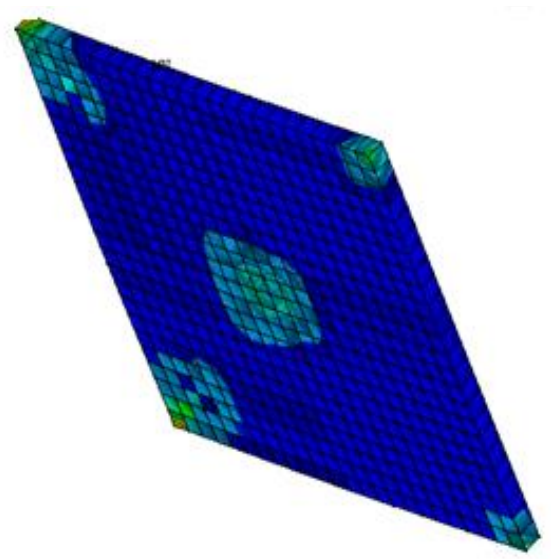

Fig. 4 Meshing seed for the platform

\section{Simulation Results and Discussions}

\subsection{Static Load Analysis}

For static analysis, we first calculated the global displacement at the top of the tower. To conduct a clear analysis, we checked each displacement when load components are added 
separately and together at the tower top. The maximum displacement of the tower occurred at the same point for the all the four structures. Exerting the loads individually, we observed that $U_{x}$ and $\varphi_{y}$ were mainly due to the load component $F_{x}$ while the displacement in the z-direction $U_{z}$ is due to the self-weight of the structure and $F_{z}$. The traditional Jackets and the twisted jackets both have similar overall displacement in all direction, which validates the fact that the twisted jacket is a robust structure with considerable load bearing capacity.

Table 4 Displacement at tower top for all models with all static loads applied

\begin{tabular}{|c|l|l|l|l|}
\hline Displacements & TJ- X & TJ-K & $30^{\circ}$ Twisted & $\mathbf{6 0}^{\circ}$ Twisted \\
\hline $\boldsymbol{U}_{\boldsymbol{X}}(\mathrm{m})$ & $0.10926 \mathrm{E}-2$ & $0.10923 \mathrm{E}-2$ & $0.17464 \mathrm{E}-2$ & $0.20929 \mathrm{E}-2$ \\
\hline $\boldsymbol{U}_{\boldsymbol{Y}}(\mathrm{m})$ & $0.14350 \mathrm{E}-3$ & $0.14335 \mathrm{E}-3$ & $0.11165 \mathrm{E}-3$ & $0.10861 \mathrm{E}-3$ \\
\hline $\boldsymbol{U}_{\boldsymbol{Z}}(\mathrm{m})$ & $0.74911 \mathrm{E}-5$ & $0.75200 \mathrm{E}-5$ & $0.64269 \mathrm{E}-5$ & $0.67808 \mathrm{E}-5$ \\
\hline $\boldsymbol{\varphi}_{\boldsymbol{X}}(\mathrm{rad})$ & $0.46612 \mathrm{E}-5$ & $0.46637 \mathrm{E}-5$ & $0.57361 \mathrm{E}-5$ & $0.70616 \mathrm{E}-5$ \\
\hline $\boldsymbol{\varphi}_{Y}(\mathrm{rad})$ & $0.25098 \mathrm{E}-4$ & $0.25073 \mathrm{E}-4$ & $0.28490 \mathrm{E}-4$ & $0.31619 \mathrm{E}-4$ \\
\hline $\boldsymbol{\varphi}_{Z}(\mathrm{rad})$ & $0.68415 \mathrm{E}-6$ & $0.75055 \mathrm{E}-6$ & $0.33005 \mathrm{E}-6$ & $0.14990 \mathrm{E}-5$ \\
& & & & \\
\hline
\end{tabular}

Furthermore, the individual reaction at mudline for all the jackets are provided in Table 5. When all the external forces were applied together, the summed reaction forces in different direction $\left(F_{x} F_{y}\right.$ and $F_{z}$ ) of all the models were equal to the corresponding load components applied to the models as we expected. When the static loads were applied separately, the result shows a regular and symmetrical characteristic for the traditional jackets and the twisted jackets. For instance, when only the external force $F_{z}$ was applied to the models, it helps us to better understand the structural behavior of the jacket models.

To sum up the static analysis, the von Mises stress was investigated. The maximum stress for all the jackets occurred at the platform, at the point of connection between the transition piece and the platform mainly due to the dead load of the tower. The minimum von Mises stress at the platform was obtained in the twisted jacket (30 degrees). The magnitude and location of the maximum von Mises stress show that the platform is susceptible to more stress and that this stress can be better distributed or decreased by attaching extra diagonal braces to connect the transition piece and the platform. 
Table 5 Reaction forces at mud-line for all jacket legs

\begin{tabular}{|l|c|l|l|l|l|}
\hline \multirow{2}{*}{ Leg } & Reaction (N) & TJ- X & TJ-K & $\mathbf{3 0}^{\circ}$ Twisted & $\mathbf{6 0}^{\circ}$ Twisted \\
\hline \multirow{4}{*}{ L1 } & $F_{x 1}$ & -88.261 & -90.821 & -516.70 & -680.13 \\
\cline { 2 - 6 } & $F_{y 1}$ & -109.76 & -106.69 & -219.49 & -379.90 \\
\cline { 2 - 6 } & $F_{z 1}$ & -1011.0 & -1005.3 & -5981.6 & -5177.2 \\
\hline \multirow{4}{*}{ L2 } & $F_{x 2}$ & -281.01 & -278.47 & -185.12 & -170.53 \\
\cline { 2 - 6 } & $F_{y 2}$ & 288.25 & 280.14 & 486.57 & 704.59 \\
\cline { 2 - 6 } & $F_{z 2}$ & 2912.1 & 2907.3 & 8875.4 & 8672.8 \\
\cline { 2 - 6 } & $F_{x 3}$ & -266.73 & -264.23 & -38.181 & 110.67 \\
\cline { 2 - 6 } & $F_{y 3}$ & 286.77 & -278.68 & -265.59 & -323.20 \\
\hline \multirow{2}{*}{ L4 } & $F_{x 4}$ & -104.01 & -106.48 & - & - \\
\cline { 2 - 6 } & $F_{y 4}$ & 109.79 & 106.73 & - & - \\
\cline { 2 - 6 } & $F_{z 4}$ & -1162.1 & -1157.3 & - & - \\
\hline
\end{tabular}

\subsection{Modal Analysis}

The Eigen period/mode is an intrinsic characteristic of the structure and is only determined by the mass distribution and the stiffness of the structure. At the Eigen period jackets oscillates easily, that will display significant resonance, that will lead to great damage of the substructure over it long-time life span. In order to avoid the maximum dynamic stress from the highest vibration velocity, foundation designers need to ensure the model Eigen period of the structure comes as far as possible from those environmental periods. Evaluating the first 10 Eigenfrequencies from all the four jackets shows that the twisted jacket substructures of $30^{\circ}$ and $60^{\circ}$ twist angle had lower Eigen-frequencies in general. The two twisted jackets have first natural frequencies of $0.29 \mathrm{~Hz}$ and $0.31 \mathrm{~Hz}$ and thus fall under the soft-stiff design category while the four-legged traditional jackets were categorized as stiff-stiff designs. We also observed that the first natural frequencies of all the jacket substructures investigated in this research were far from the typical wave period of $4 \mathrm{~s}$, which implies that for normal wave loads, the structure resonance seldom happens. Nevertheless, in order to comprehend the possible vibration movement, the Eigen mode of the jackets is investigated. As the response primarily depends on the global Eigen mode of the jackets, we therefore focus on the global Eigen mode and make comparison between different models. Fig. 5 below illustrates the first four Eigen mode of the traditional X-braced jacket substructure. 

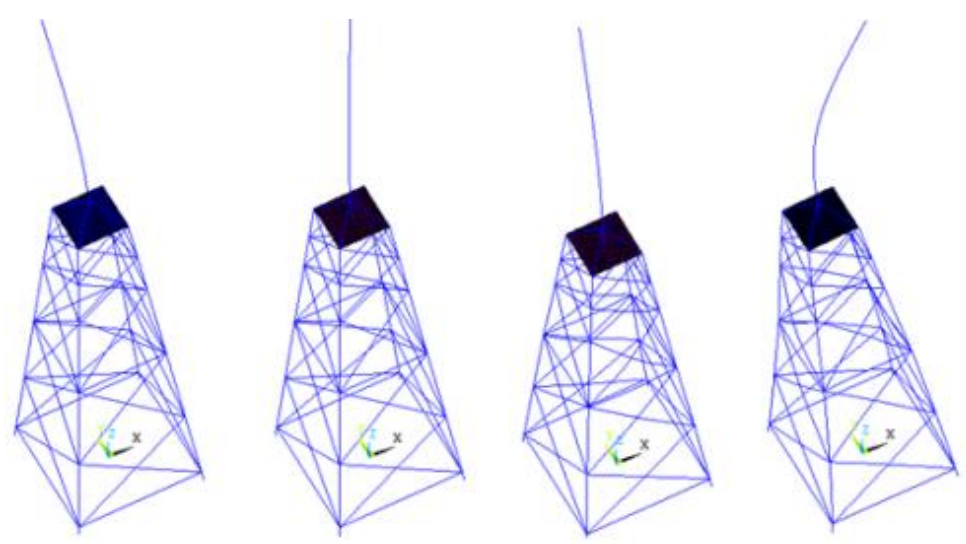

Fig. 5 Oscillation of traditional X-braced jacket

The traditional jacket with X-bracing oscillate significantly in the first, third and fourth Eigen period. We also observe that the structure is globally moving in the first Eigen period, with the tubular tower moving in the y direction and the jacket in stationary position. The global oscillation of the third Eigen mode is the same as the first one. The difference between the first and the fourth mode is that in the fourth mode the tower bend in the $\mathrm{x}$ direction. There is an up and down vibration of braces in the $5^{\text {th }}$ to $8^{\text {th }}$ Eigen modes which are not shown here. Because of the similarity in results between the traditional, K-braced and X-braced jackets substructure in terms of Eigen frequencies, the Eigen modes of the K-braced jacket are not further discussed. For both twisted jacket foundations, global bending was more obvious. In the first Eigen mode there is a global displacement of the tower. Vibration of the bottom braces was not visible throughout the first ten Eigen frequencies of the structure. However, global bending becomes more and more clear.

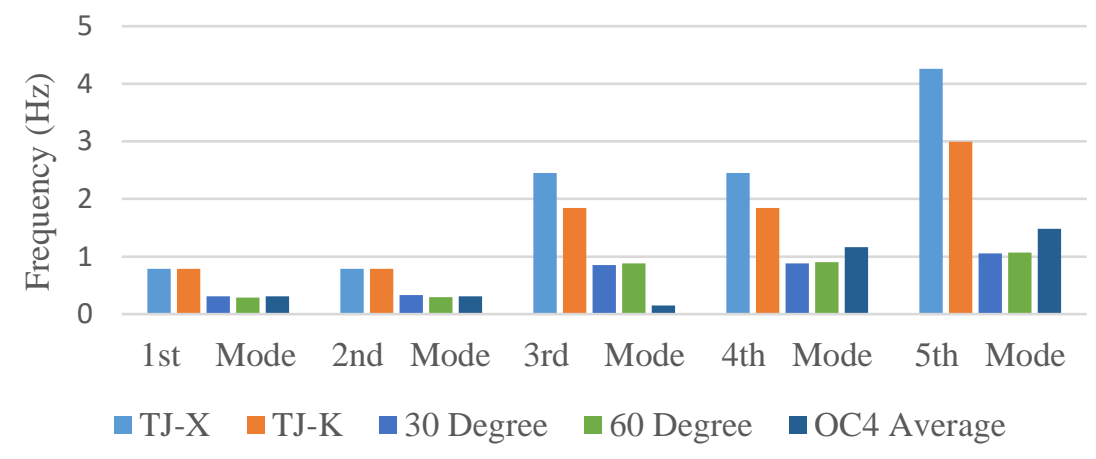

Fig. 6 First 5 modes of all models compared with OC4 average results

In Fig. 6, we continue to check the first five modes of all structures compared with the result available for the offshore code comparison collaboration continuation (OC4) project. The geometry description for the jacket in the code comparison collaboration continuation (OC4) project is outlined in [33]. In the OC4 project, the four-legged jackets were designed with four levels of $\mathrm{X}$ braces as opposed to the five levels of vertical braces in this research. The first two Eigen-frequencies of the twisted jackets (30 and 60 degrees) are much more comparable to those of the OC4 average. This result only serves as a preliminary check for the validity of the jacket foundations. For future coupled simulations, a more accurate Rotor Nacelle Assembly (RNA) should be used. As Jacket foundations are susceptible to dynamic loads, the continual change in both magnitude and direction of the external loads, such as wave and current, can 
lead to scour to the piles that connect the jackets to the seabed. This, in turn, will weaken the load capacity of the jackets, even though the scour only causes a small change in the structural stiffness of the foundation.

\subsection{Dynamic analysis}

To investigate the dynamic behavior of the jacket foundations, a finite element method was applied to carry out time-history simulation analysis. The time duration representing a particular length of history output in the time step of the simulation is set to $120 \mathrm{~s}$, over which the peak displacement responses of structures under wave load excitations are observed. The structural response subjected to wave and wind loadings were calculated separately for all the jackets. In this dynamic analysis, it was observed that the most critical areas are regions just above the mean sea level such as the splashing zones. The effect of the wave load is high at regions above the mean sea level like the splashing zones and additional bracing should be considered to redistribute the stress.

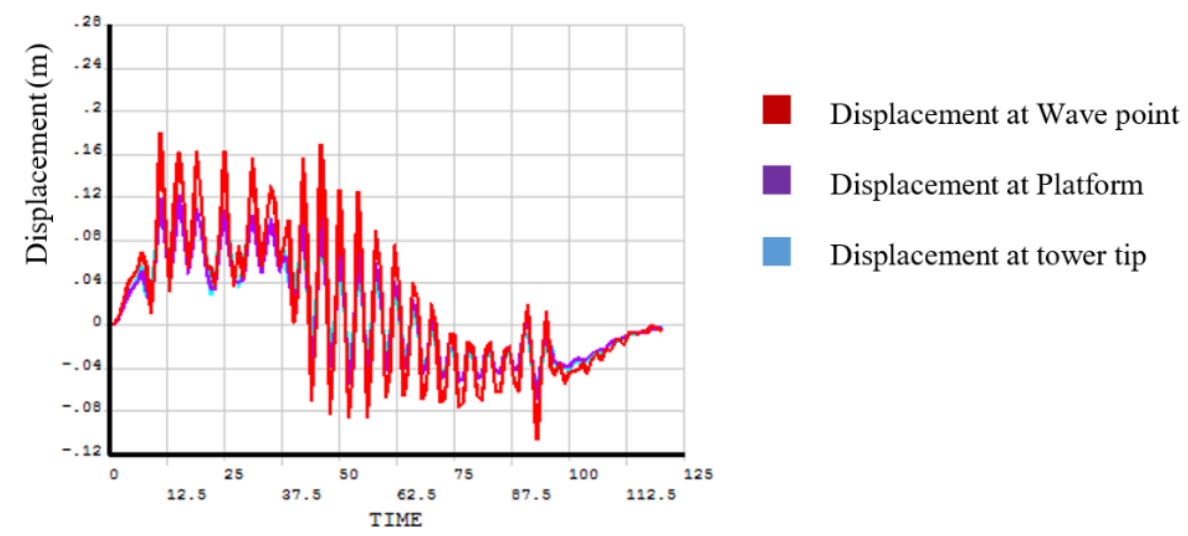

Fig. 7 Displacement of 30 Degree Twisted Jacket at Wave Point, platform and tower top in X Direction

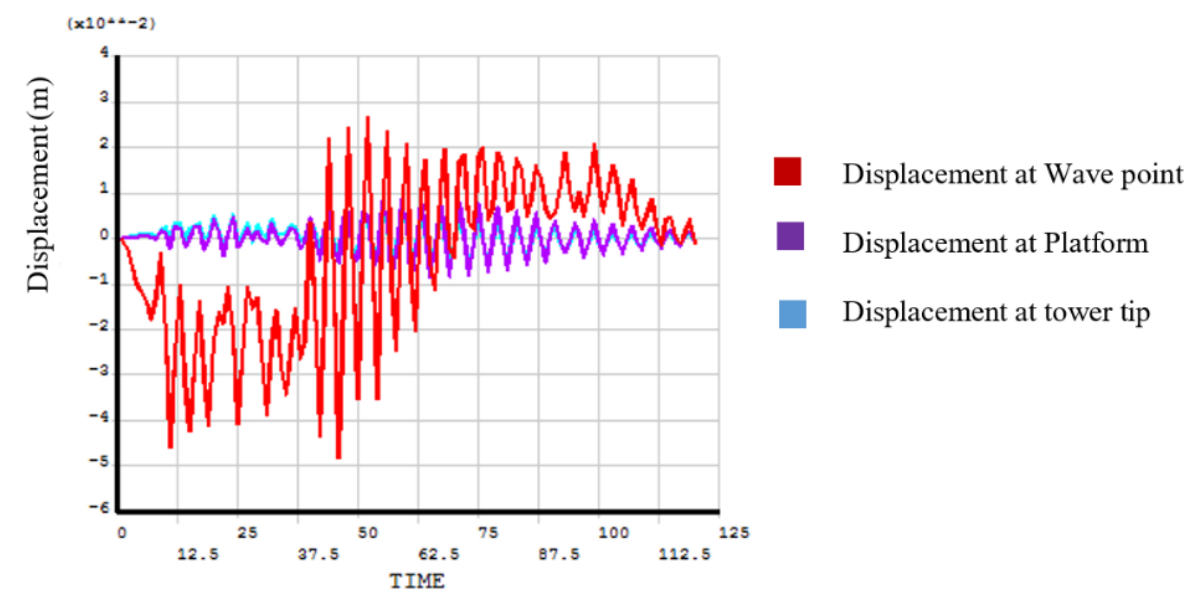

Fig. 8 Displacement of 30 Degrees Twisted Jacket at Wave point, Platform and tower top in Y Direction

The various displacement responses due to wave load are presented in Fig. 7 to Fig. 11 and show that a variation in displacement in $\mathrm{X}, \mathrm{Y}$ and $\mathrm{Z}$ axis at the mean sea level, tower tip and platform was observed for all jackets foundations. This may result from the presence of braces in different planes which has effect on the stress distribution in the joint either by increasing stiffness or weakening the joint. Given that the first natural frequency of the twisted jackets fell between $1 \mathrm{P}$ and $3 \mathrm{P}$, the twisted jackets were classified as soft-stiff designs as expected. In the design category, the wind load could be more dangerous than wave load. Most OWTs are designed in this range(soft-stiff). 

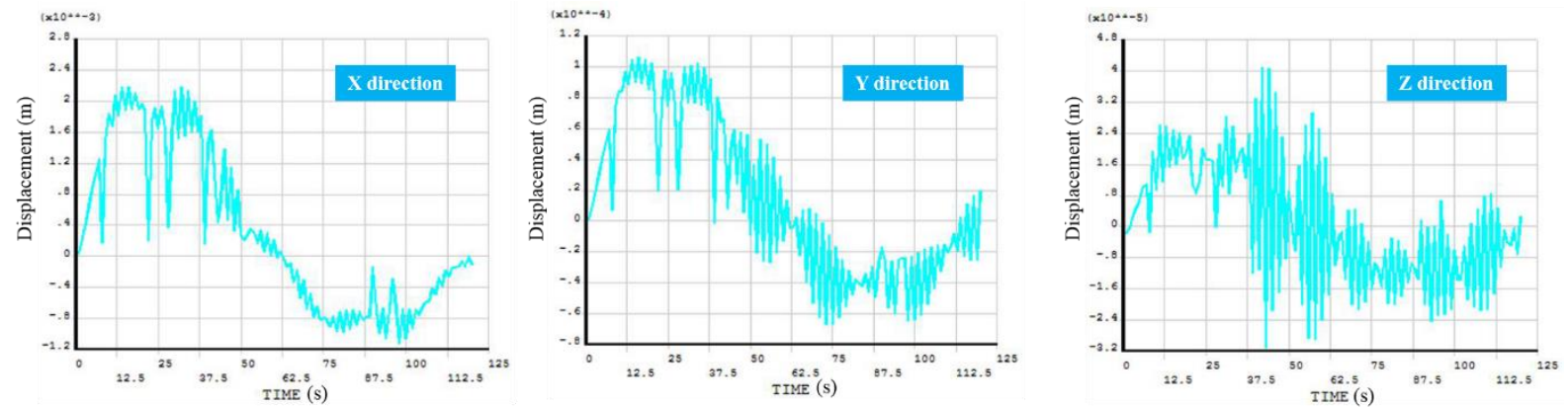

Fig. 9 Displacement of Traditional X-Bracing Jacket at Wave point in the $\mathrm{X}, \mathrm{Y}$ and $\mathrm{Z}$ directions
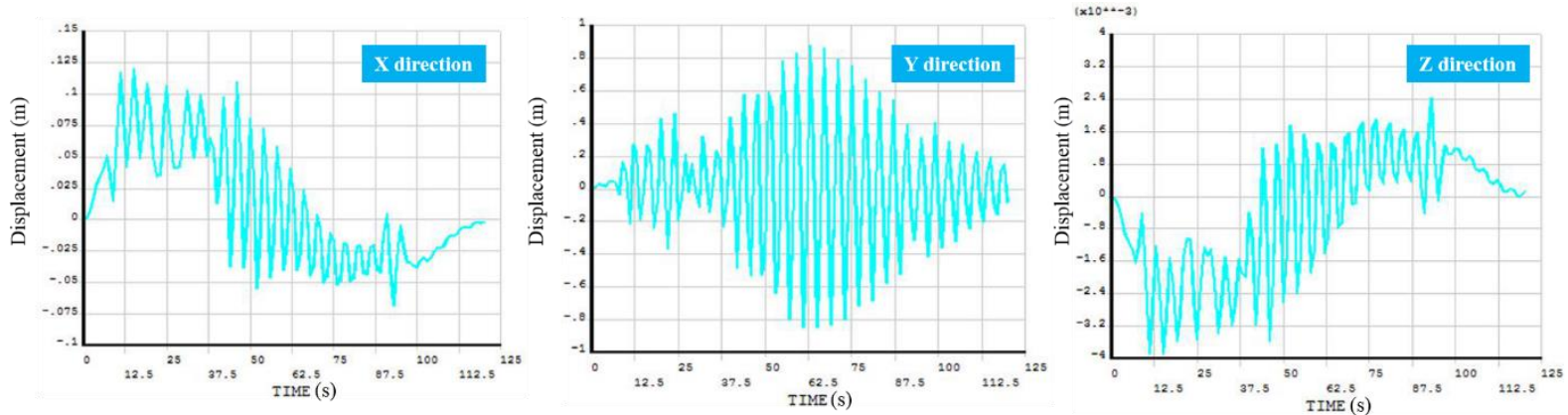

Fig. 10 Displacement of Traditional X-Bracing Jacket at Platform in the X, Y and Z directions
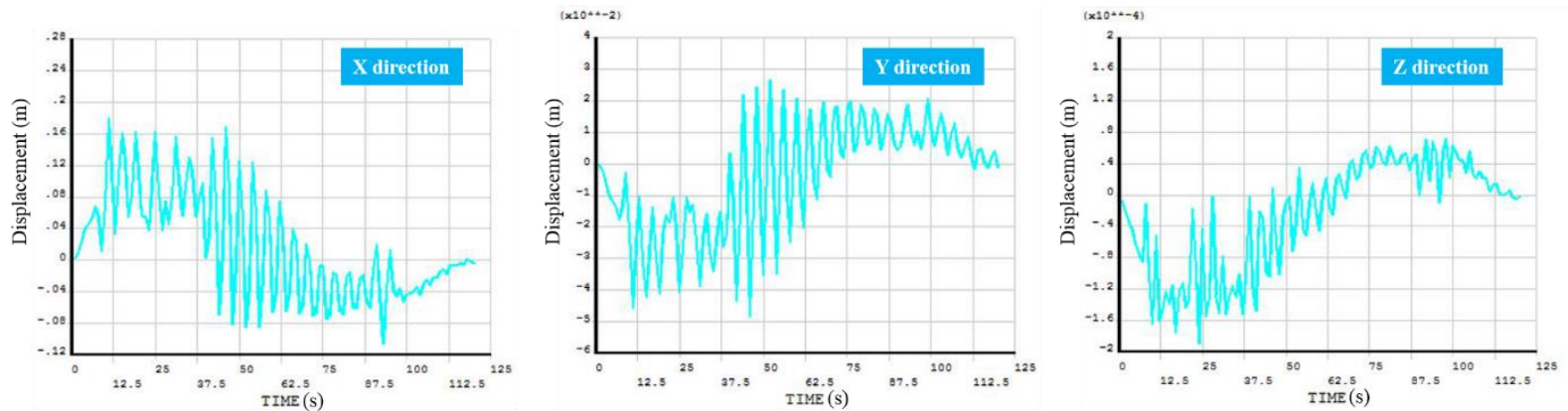

Fig. 11 Displacement of Traditional X-Bracing Jacket at Tower Tip in the X, Y and Z directions

In reality, jacket foundations are subjected to unpredictable time varying hydrodynamic forces. For instance, wave load goes through various nonlinear changes such as wave breaking and shoaling. A proper investigation of these wave impulsive wave forces is thus essential because these slamming forces from the wave might impede the structural integrity and fatigue life of the jacket foundation.

\section{Conclusions and Recommendations}

The structural static and dynamic performance of four jacket foundations ( 2 conventional four-legged and 2 twisted jackets) has been investigated by numerical simulations. From the results of this study, the main conclusions can be drawn as follows:

Cost-efficiency: We observed that the three-legged twisted jackets could prove to be costefficient jacket foundation in transitional water depth in comparison to the traditional four-legged jacket due to considerable reduction in joints and mass.

Modal and Dynamic Analysis: The natural frequencies of all the four jackets were far away from resonance and within the safe operating limits. The two traditional four-legged 
jackets had a lower Eigen-period of about 1.26 seconds. It is recommended that future natural frequency design should be based on improvement of tower substructure not the variation in the jacket foundation. The jacket foundations have excellent stiffness and lower masses in comparison to the tower.

Static Analysis: Similarly, the results of the static analysis revealed that all the jacket foundations were structurally safe under the provided load combinations. The twisted jackets showed excellent structural behaviour compared to the traditional jackets, while maintaining the advantage of fewer material usage and joint. Furthermore, additional bracings are relevant to reduce the maximum stress at the area of connection between the transition piece and the platform especially for the traditional jackets. The centre sleeve in the twisted jackets helped minimize the stress at the same location.

\section{Acknowledgements}

This work is supported by the Key project of NSFC-Shandong joint research POW3C (U1906230), Zhejiang Provincial Key Laboratory for offshore wind technology in deep sea (ZOE2020003) and fundamental research funds for the central universities (3072020CFT0204).

\section{REFERENCES}

[1] WindEurope, "The European Offshore Wind Industry-Key Trend and Statistics ", 2016. [Online]. Available: https://windeurope.org/about-wind/statistics/

[2] WindEurope, "The European offshore Wind Industry-Key Trend and Statistics ", 2017. [Online]. Available: https://windeurope.org/about-wind/statistics/

[3] WindEurope, "The European offshore wind industry-Key Trend and Statistics ", July 20162018. [Online]. Available: https://windeurope.org/about-wind/statistics/

[4] 4COffshore. Alpha Ventus Offshore Wind farm [Online] Available: https://www.4coffshore.com/windfarms/alpha-ventus-germany-de01.html

[5] J.H Zhang, I Fowai , Sun K . "A glance at offshore wind turbine foundation structures". Brodogradnja, vol.67, no.2,pp.101-113,2016. https://doi.org/10.21278/brod67207

[6] Intellisims, "ijacket Technology and Innovation," 2019. [Online]. Available: http://intellisims.com/ijacket.html

[7] A. M. Page, A. Løkke, K. S. Skau, and J. B. De Vaal, "A Family of Practical Foundation Models for Dynamic Analyses of Offshore Wind Turbines," in Offshore Technology Conference, 2019: Offshore Technology Conference. https://doi.org/10.4043/29463-MS

[8] K. Abhinav and N. Saha, "Nonlinear dynamical behaviour of jacket supported offshore wind turbines in loose sand," Marine Structures, vol. 57, pp. 133-151, 2018. https://doi.org/10.1016/j.marstruc.2017.10.002

[9] P. Agarwal and L. Manuel, "Simulation of offshore wind turbine response for long-term extreme load prediction," Engineering structures, vol. 31, no. 10, pp. 2236-2246, 2009. https://doi.org/10.1016/j.engstruct.2009.04.002

[10] P. Haselbach, A. Natarajan, R. G. Jiwinangun, and K. Branner, "Comparison of coupled and uncoupled load simulations on a jacket support structure," Energy Procedia, vol. 35, pp. 244-252, 2013. https://doi.org/10.1016/j.egypro.2013.07.177

[11] J. J. Jensen, A. S. Olsen, and A. E. Mansour, "Extreme wave and wind response predictions," Ocean engineering, vol. 38, no. 17-18, pp. 2244-2253, 2011. https://doi.org/10.1016/j.oceaneng.2011.10.003

[12] S. H. Ju, F. C. Su, Y. T. Jiang, and Y. C. Chiu, "Ultimate load design of jacket-type offshore wind turbines under tropical cyclones," Wind Energy, vol. 22, no. 5, pp. 685-697, 2019. https://doi.org/10.1002/we.2315 
[13] M. Mardfekri and P. Gardoni, "Probabilistic demand models and fragility estimates for offshore wind turbine support structures," Engineering Structures, vol. 52, pp. 478-487, 2013. https://doi.org/10.1016/j.engstruct.2013.03.016

[14] N. Saha, Z. Gao, T. Moan, and A. Naess, "Short-term extreme response analysis of a jacket supporting an offshore wind turbine," Wind Energy, vol. 17, no. 1, pp. 87-104, 2014. https://doi.org/10.1002/we.1561

[15] M. Seidel, M. Von Mutius, P. Rix, and D. Steudel, "Integrated analysis of wind and wave loading for complex support structures of Offshore Wind Turbines," Proceedings of Copenhagen Offshore Wind, pp. 26-28, 2005.

[16] C. Latini, "Numerical modelling of offshore foundations for jacket structures," Technical University of Denmark, Department of Civil Engineering, 2018.

[17] J. Häfele, C. G. Gebhardt, and R. Rolfes, "A comparison study on jacket substructures for offshore wind turbines based on optimization," Wind Energy Science 4 (2019), vol. 4, pp. 23-40, 2019. https://doi.org/10.5194/wes-4-23-2019

[18] J. Häfele, "A numerically efficient and holistic approach to design optimization of offshore wind turbine jacket substructures," Hannover: Institutionelles Repositorium der Leibniz Universität Hannover, 2019.

[19] B. Nelson and Y. Quéméner, "Fatigue Life Analysis of Offshore Wind Turbine Support Structures in an Offshore Wind Farm," in ASME 2018 1st International Offshore Wind Technical Conference, 2018: American Society of Mechanical Engineers, pp. V001T01A039-V001T01A039. https://doi.org/10.1115/IOWTC2018-1061

[20] Y. Wu et al., "Fatigue Calculation of Offshore Jacket Structural For Monitoring," in IOP Conference Series: Materials Science and Engineering, 2019, vol. 588, no. 1: IOP Publishing, p. 012015. https://doi.org/10.1088/1757-899X/588/1/012015

[21] A. Glisic, N.-D. Nguyen, and P. Schaumann, "Comparison of Integrated and Sequential Design Approaches for Fatigue Analysis of a Jacket Offshore Wind Turbine Structure," in The 28th International Ocean and Polar Engineering Conference, 2018: International Society of Offshore and Polar Engineers.

[22] D. Augustyn, M. B. Nielsen, and R. R. Pedersen, "17.04: Design of offshore wind turbine jacket foundations: On the influence of subsequent modifications on fatigue performance," ce/papers, vol. 1, no. 2-3, pp. 4323-4332, 2017. https://doi.org/10.1002/cepa.491

[23] J.H Zhang, Won-Hee Kang, Ke Sun, and F.S Liu. "Reliability-Based Serviceability Limit State Design of a Jacket Substructure for an Offshore Wind Turbine", Energies, vol.12,no.14, pp.2751-16 2019. https://doi.org/10.3390/en12142751

[24] B. Yeter, Y. Garbatov, and C. Guedes Soares, "Ultimate strength assessment of jacket offshore wind turbine support structures subjected to progressive bending loading," Ships and Offshore Structures, vol. 14, no. 2, pp. 165-175, 2019. https://doi.org/10.1080/17445302.2018.1484030

[25] S. Han, K. Lee, B.-S. Jang, and J. Choi, "A Study on the Effect of Soil Properties on Structural Behavior of Fixed Jacket Type Offshore Structure," Journal of the Society of Naval Architects of Korea, vol. 55, no. 5, pp. 438-447, 2018. https://doi.org/10.3744/SNAK.2018.55.5.438

[26] Design of Steel Structures, Standard N-004, NORSOK, 2004. [Online]. Available: http://www.dnv.com

[27] Design of Steel Structures, Standard N-004, NORSOK, 2013. [Online]. Available: http://www.dnv.com

[28] Design of Offshore Wind Turbine Structures, D. N. V. AS, 2014. [Online]. Available: http://www.dnv.com

[29] S. B. J.Jonkman, W. Musial, and G.Scott, "Definition of a 5-MW Reference Wind Turbine for Offshore System Development," NREL, NREL/TP-500-38060, 2009. https://doi.org/10.2172/947422

[30] Chen, I-Wen, et al. "Design and analysis of jacket substructures for offshore wind turbines."Energies 9.4 (2016): 264. https://doi.org/10.3390/en9040264

[31] Devaney, Louise Claire. Breaking Wave Loads and Stress Analysis of Jacket Structures Supporting Offshore Wind Turbines. Diss. University of Manchester, 2012.

[32] http://mechanika2.fs.cvut.cz/old/pme/examples/ansys55/html/guide_55/g-str/GSTRToc.htm. Ansys Structural Analysis Guide

[33] Vorpahl, Fabian, Wojciech Popko, and Daniel Kaufer. "Description of a basic model of the" UpWind reference jacket" for code comparison in the OC4 project under IEA Wind Annex XXX." Fraunhofer Institute for Wind Energy and Energy System Technology (IWES), Germany (2011). 
Issa Fowai, Zhang Jianhua, Ke Sun,Bin Wang
Structural Analysis of Jacket Foundations for offshore wind turbines in transitional water
Submitted: $\quad$ 09.03.2020.

Accepted: $\quad$ 10.04.2021.
Issa Fowai, Zhang Jianhua

College of Aerospace and Civil Engineering,

Harbin Engineering University

Ke Sun* (Corresponding author)

College of Shipbuilding Engineering, Harbin

Engineering University, Harbin, China

sunke@hrbeu.edu.cn

Bin Wang

Powerchina Huadong Engineering Corporation

Limited 